\title{
Mathematical Modeling of Multiple Intelligence Theory Based on Information Entropy Theory
}

\author{
Xudong Yang \\ Physical Education Department,Hetao College,Bayannaoer, China \\ y_ang_xudong@126.com
} Keywords: optimization theory; advantages integration; mathematical modeling; potential
excitation; characteristic function

\begin{abstract}
Table tennis is a popular sport in the world, but also is the Chinese country ball, the integration of pluralistic intelligence theory and table tennis teaching is need of physical education reform and development under the modernization education background. Based on the multiple intelligence theory, modern physical teaching is the important significance, to carry out deepening analysis of the integrating advantages of multiple intelligences theory and table tennis teaching, the use of mathematical modeling constructs table tennis teaching methods under the optimization multiple intelligences theory, to provide theoretical basis and practice new path for the modern table tennis teaching.
\end{abstract}

\section{Introduction}

Since 1990s, Howard Gardiner professor had put forward the multiple intelligences theory, which had been caused extensive positive effect in the United States and the world scope, and was rapid development of the western countries education reform development direction as important guiding ideology. In our country, pluralistic intelligence theory research is very common to deepen the education reform and the full implementation of quality education situation, especially the diversity theory is particularly outstanding in the influence of education and teaching reform. For example Zhan Bingju's multiple intelligence theory and its enlightenment on quality education, he was mainly from two aspects to carry on research that were respectively psychology and educational psychology, in view of our country quality education's multiple intelligences education theory, education idea and teaching practice were discussed, and according to the needs of students comprehensive development, based on the multiple intelligences theory teaching environment, to establish a diversified curriculum, then to put forward to improve the students comprehensive quality's training programmer [1]; Feng Rui and Zhu Yan's web course design based on multiple intelligence theory, based on the multiple intelligence theory, the design orientation transition of network course is from target, content, environment, evaluation's four aspects to carry on the discussion [2]; Su Juan's teaching experiment of multiple intelligence theory and physical education curriculum development, to create new pattern of sports curriculum multiplication development for breaking the single pattern of sports curriculum, to carry on the research analysis of multiple intelligences theory, and then to construct a set having a plurality, multidimensional and development curriculum system[4]. Combined with the predecessors' studies of our country education, not difficult discovery is generally based on the multiple intelligences theory to carry out the necessary analysis, and links to our current educational environment on the education concepts, teaching practice, curriculum design, educational reform and other aspects, to propose constructive suggestions. Based on the predecessor on diversity theory and on the basis of education teaching analysis, the table tennis teaching method research will open up new ways that have profound practical significance of demand [5].

\section{The significance of multiple intelligence theory on modern physical teaching}

The traditional physical education is only language and physical knowledge skills training, which do not pay enough attention to human comprehensive training, such as the cultivation object's selfcognition, vocal, collaboration-space observation, natural understanding and so on, to a certain 
extent affect the students' all-round development and reduce the efficiency of learning, the success road of students does not play a positive role, at the same time causing part of the waste of human resources [6,7].

With the development of multiple intelligence theory, it gradually becomes the important proposition of Chinese curriculum reform. The multiple intelligences theory is proposed by American psychologist Gardiner, its theory emphasizes on the human intelligence that is pluralistic, everyone has at least 8 or more kinds of intelligence, and these are basic human skills, however human performance is different because the human potential excitation level is different, its eight basic multiple intelligent is shown in Figure 1.

In Figure 1, Gardiner's multiple intelligence has eight basic skills, it is concentrated on the language (listen, say, read, writing), mathematics (arithmetic and reasoning ability), visual (perception, discrimination, memory, emotional), physical (use of limbs and trunk capacity), insight (person get along and skills ), music (perception, discrimination, memory, change and expression musical abilities), natural (understanding, insight and reflect on own emotion, motivation, desire, will, personality) and interpersonal (identify things and perceived nature characteristics abilities), which is a departure from the angle of human comprehensive development $[9,10]$.

The application of multiple intelligence can not only improve the physical education teaching achievements in PE teaching, but also can promote all-round development of students in many aspects ability, cultivate students' comprehensive qualities; in physical education, the multiple intelligence can be applied for the current students personalized characteristic feature analysis, to further deepen physically labor-round development of physical teaching and modern teaching syllabus requirements; in sports teaching, the application of multiple intelligence can optimize teaching concept, teaching content, changing teaching mode and construction optimization sports teaching method [11]; it is decomposed teaching goal that can carry on hierarchy and diversity combining, the use of modern multimedia technology to construct diversified teaching environment; it can develop subject teaching, reflecting the subjectivity of students and cooperation and mutual assistance, learning mode of individuality and group, to promote the many aspects of contemporary students' intellectual development in the physical education [12].

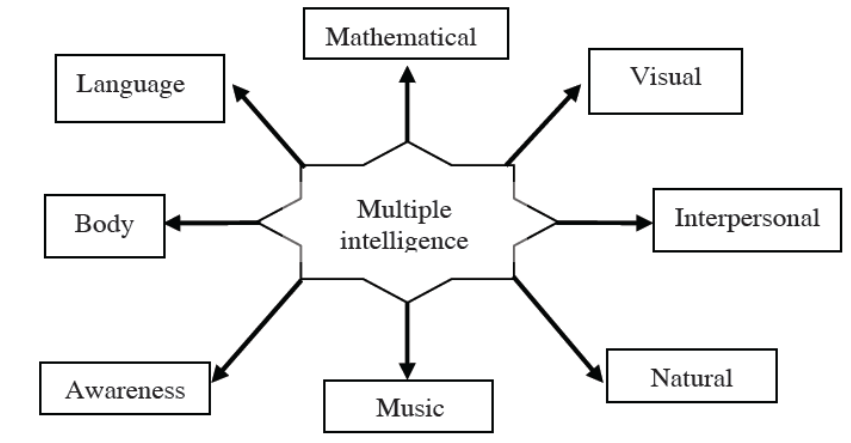

Figure 1. Multiple intelligences eight basic intelligence

\section{The integrated advantage analysis of multiple intelligences theory and table tennis teaching}

The starting point and destination of table tennis teaching is the development of students, and to inspire and train students' comprehensive ability is the essential requirement of quality education. From the trend of future education, multiple intelligence theory has the widespread application prospect in the table tennis teaching and sports teaching. The traditional sports teaching process is teacher, student $[13,14]$, teaching content and other elements, to form a closed circle of interaction in the study, its specific processes are shown in Figure 2.

In Figure 2, the process of traditional table tennis teaching is single, which is lack of effective interaction and diversity. In the actual integration process of multiple intelligences theory, it can mine ample resources for the study of multiple Intelligences theory, and can carry on analysis of characteristic index, to develop and train each students' potential, the development of independent personality, thought and stimulation students' innovation ability, to make the teaching better results. The integration of multiple intelligences theory and table tennis teaching will break through the traditional teaching mode, to make every student participate in the teaching practice, to provide the 
opportunity for every student, and to try to obtain the experience of success. In order to arouse people rethink on education, multiple intelligence theory is proposed that can evokes a rethink on education. The table tennis teaching advantages of multiple intelligences theory are shown in Figure 3.

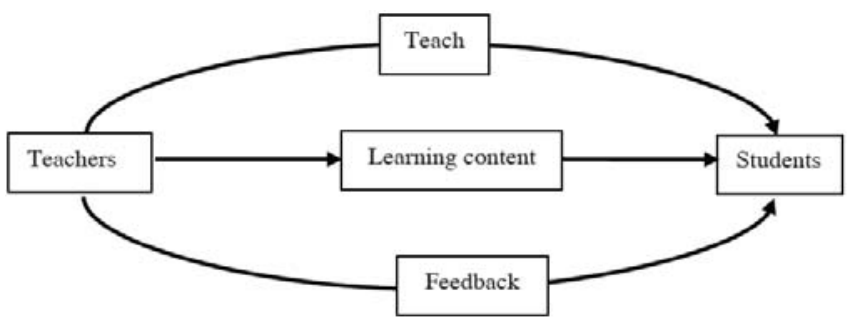

Figure 2. The traditional tennis teaching process

In Figure 3, the integration advantages of multiple intelligences theory and table tennis teaching can be used the process of learning, and physical education teaching can not be influenced by the limits of traditional method, when encountering problems, it can be multi-directional and multi-angle level to find the answer; in the teaching, more important is the adoption of new learning methods and learning thinking mode, the cultivation of students' comprehensive awareness and spirit; In the process of learning, motivate students dare to innovate, questioning and criticism; to explore student's independent thinking ability and the acts understanding and expression ability of individual characteristics; in teaching new method, the integration students can be active learning and improve their practice ability [15], so the multiple intelligence theory can be integration with table tennis teaching.

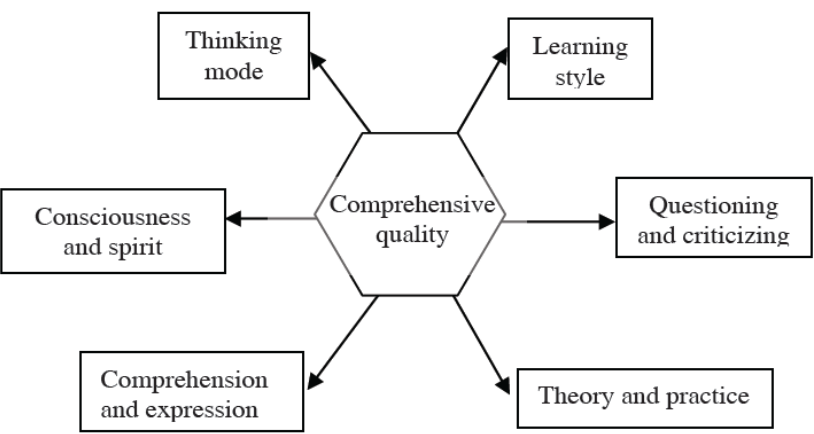

Figure 3. The integration advantages of multiple intelligence theory and table tennis teaching

\section{The construction of table tennis teaching mode under the optimization multiple intelligences theory}

The integration of multiple intelligences theory and table tennis teaching can make teachers open up their teaching ideas in the process of physical education learning, expand their thinking, divergent their teaching skills and change traditional teaching mode, its integration teaching way as shown in Figure 4.

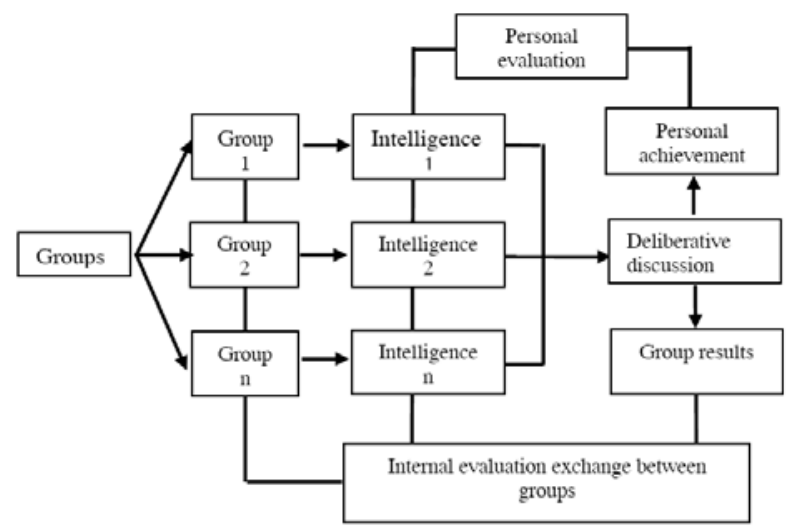

Figure 4. Table tennis teaching mode under the optimization multiple intelligences theory

In Figure 4, students should grasp the learning important point in the learning process, imagined that $\mathrm{m}$ students accept a sports activities education. For students, no matter how many people constituting a cooperative (single as individual cooperation) will obtain some results, however the 
competition between students are non confrontational, so the number of students will not cause the harvest reduced in the cooperation, the cooperation of all $\mathrm{m}$ students will reap the greatest harvest [16].

A collection of $m$ individuals and all kinds of possible cooperation's benefit can make m person cooperative game, let $\mathrm{m}$ students cooperative intelligence $I=\{1,2, \cdots, n\}$ that is equal status, its interests are non confrontational; all combinations, $s \subseteq I$ are regarded as a cooperative and can create some gains $v(s)$; all m personal cooperation $I=\{1,2, \cdots, n\}$ will bring the greatest harvest, and $\mathrm{n}$ personal single learning receive minimum overall harvest. Set $u$ and $v$ are both m people multiple intelligence's characteristic function, if a member $i, \forall s \subseteq I$ is $v(s)=v(s \cup\{i\})$ or $\varphi_{i}(v)=0$; at the same time, $\sum_{i=1}^{n} \varphi_{i}(v)=v(I)$, namely students $i$ are not able to have a good harvest; set $v_{1}$ and $v_{2}$ are m person multiple intelligence's characteristic function, it can get $u=v_{1}+v_{2}$; for $\forall s \subseteq I$, there are $u(s)=v_{1}(s)+v_{2}(s)$ that is m person cooperative game's characteristic function, at this point there should be $\varphi(u)=\varphi\left(v_{1}\right)+\varphi\left(v_{2}\right)$; when $I$ simultaneously carries out two intelligence education cooperation, and each student gains equal to two intellectual cooperation harvest and, i.e. to strengthen the training education of students' comprehensive ability, teachers are not only to impart knowledge information in the classroom teaching process, and simultaneously is also the emotion exchange, it is demonstrated as follows:

$$
\left\{\begin{array}{l}
\left.\varphi_{i}(v)=\sum_{i \in s} w(|s|) \mid v(s)-v(s \backslash\{i\})\right] i=1, \ldots, n \\
w(|s|)=\frac{(n-|s|) !(|s|-1) !}{n !}
\end{array}\right.
$$

$|s|$ is said the number of elements in $s$ set. From the goal of our country educational reform pursuit starting, the design of diversification teaching goals and teaching situation, to carry out diversified learning mode and individualized training plan. Since ancient times, pluralistic intelligence theory combined with the weight of practice teaching that can not be underestimated in the teaching of table tennis, many teaching methods are derived from the teaching practice from the multiple intelligences theory on modern teaching, the integration advantage analysis of multiple intelligences theory and table tennis teaching, table tennis teaching mode under the optimization multiple intelligences theory to construct the table tennis teaching mode of multiple intelligences theory. So this gives a full array of $P_{1}, P_{2} \cdots P_{|s|-1}, i, P_{|s|+1}, \cdots, P_{n} \quad$, Among them, $s=\left\{P_{1}, P_{2} \cdots P_{|s|-1}, i\right\}(\subseteq I) ; s /\{i\}=\left\{P_{1}, P_{2} \cdots P_{|s|-1}, i\right\} \quad$ can be said appear multiple intelligence characteristic index in front of $i$, if $i$ is increased, it can increase the harvest index; if the increased part harvest are all $i$, apparently from the point of $i$ to see, it should be a " satisfactory ". However the emergence of this' opportunities are random, $s /\{i\}$ appears before $i$, however $I / s=\left\{P_{|s|-1}, \cdots, P_{n}\right\}$ happens to appear probability that is $w(|s|)=\frac{(n-|s|) !(|s|-1) !}{n !}$. In the objective world of a random, $i$ can take all possible increase harvest in table tennis teaching, which can get:

$$
\varphi_{i}(v)=\sum_{s \in S_{i}} w(|s|)[v(s)-v(s \backslash\{i\})]
$$

In the actual teaching process, to grasp the knowledge points and thinking awareness on the macro and micro can be better integration of learning content and learning method, to make the table tennis learning and other disciplines learning can be achieved excellent results in sports class, at the same time to make the geography courses teaching has more profound, flexibility, openness and other characteristics. Under the optimization of multiple intelligence theory, table tennis teaching methods' innovation consciousness is the people engaged in the activities of the starting point and driving force, which is a found problem and the psychological orientation actively explore. 


\section{Conclusion}

The Lecture Notes in Computer Science volumes are sent to ISI for inclusion in their Most of the people restrict to language and mathematical intelligence training on the general understanding concept of traditional intelligence, ignoring the movement, music, relationships, self-perception, space and natural observation ability, thereby hindering students multifaceted development opportunities. On the intelligent element, its influence is lack of understanding and attention in the education and teaching, which will block students the channel of achievements, causing the passing of a brain and the great waste of manpower resource. In the rapid development of science and technology, the innovation spirit has become more great attention; more efficient training new-type talents are one of the serious problems facing in education. Through constant change, finally to form a strict teaching system and teaching management method, and to adhere to the health education teaching mode, on the basis of multiple intelligences theory, to carry on the high-quality talents of comprehensive cultivation, the multiple intelligence theory is integrated into the table tennis teaching practice.

\section{References}

[1] Zhan Bingju. Enlightenment of multiple intelligence theory on quality education. Shandong normal university, 2009:3-15.

[2] Feng Rui, Zhu Yan. Network curriculum design based on the multiple intelligence theory . Chinese audio-visual education, 2009(6): 112-113.

[3] Tian Youyi. The multiple intelligence theory and its significance on education . Journal of higher correspondence education (Philosophy and social sciences edition), 2009(1): 89-90.

[4] Zhu Min. Research on curriculum design of the perspective of multiple intelligences theory. East China normal university, 2009: 1-10.

[5] Su Juan. Teaching experiment of multiple intelligence theory and sports curriculum development . Journal of Wuhan sports institute, 2010(6): 45-46.

[6] Qin Xiaohui. The training of multiple intelligence theory and students comprehensive ability . Modern communication, 2011(12): 78-79.

[7] Peng Hongying. The application of multiple intelligences theory in the course of computer culture basis . Journal of Shanxi normal university (Natural social sciences edition), 2010(3): 121122.

[8] Su Piren. Table tennis tutorial . Higher education press, 2009: 145-156.

[9] Zhang Bo, Zhan Lilai. Table tennis revolving techniques . People's sports, 2009: 167-174.

[10] Pan Sheyi. Table tennis tutorial . Beijing institute of technology press, 2011: 60-83.

[11] Wu Zhaoxiang. Table tennis . Anhui people's press, 2010: 35-50.

[12] Jia Huaiqin. Data, model and decision. International economics business university press, 2010: 213-224.

[13] Qiu Wanhua. Management decision-making and applied entropy theory . Beijing: Mechanical industry press, 2010: 112-133.

[14] Peter Egger. On the impact of transportation costs on trade in a multilateral world .Southern economic journal, 2009, 71(3): 67-68.

[15] JuliaDevlin, PeterYee. Global Links to regional networks: trade logistics in MENA countries, the Fourth Annual Mediterranean Development Forum Held in Amman, 2009(10):6-9.

[16] Kang L S Pauison B C. Information classification for civil engineering by uniclass . Constr Engrg and Mgmt ASCE Z 000 1Z 6(Z): 158-167. 